\title{
Karakteristik Bioekologi Rajungan (Portunus Pelagicus) Di Perairan Dusun Ujung Lombok Timur
}

\author{
Didik Santoso ${ }^{1}$, Karnan $^{2}$, L. Japa ${ }^{3}$, Raksun ${ }^{4}$ \\ 1,2,3,4, Program Studi Pendidikan Biologi, Jurusan PMIPA FKIP Universitas Mataram \\ Korespondensi Penulis : didiksantoso91@gmail.com
}

\begin{abstract}
ABSTRAK
Penelitian ini bertujuan untuk mengkaji ukuran rajungan yang tertangkap, menganalisis perbandingan jumlah rajungan jantan dan betina yang tertangkap, dan menganalisis karakteristik habitat (salinitas, suhu, $\mathrm{pH}$, dan bentuk dasar substrat perairan) di daerah penangkapan rajungandi Dusun Ujung Lombok Timur. Jenis penelitian ini adalah penelitian diskriptif dengan menggunakan metode survai dalam pengambilan data. Parameter yang diteliti adalah parameter biologi dan ekologi rajungan. Parameter biologi yang diamati adalah jenis kelamin, dan lebar karapas, sedangkan parameter ekologi adalah suhu, salinitas, dan $\mathrm{pH}$ perairam serta bentuk dasar substrat. Kondisi substrat didominasi oleh fraksi pasir diikuti oleh fraksi lumpur dan fraksi liat. Hasil penelitian menunjukkan bahwa kualitas air di daerah penelitian sangat sangat layak bagi kehidupan rajungan, dengan sebaran suhu antara $29^{\circ} \mathrm{C}-30^{\circ} \mathrm{C}$. Salinitas perairan di daerah penelitian berkisar dari 31 sampai $32 \mathrm{ppt}$, dan Nilai $\mathrm{pH}$ perairan di lokasi penelitian berkisar antara 7.2 sampai 7.5. Distribusi lebar karaps rajungan di dominasi oleh lebar diatas $100 \mathrm{~mm}$ baik jantan maupun betina. Proporsi lebar karapas rajungan jantan yang tertangkap dengan lebar diatas $100 \mathrm{~mm}$ adalah sebesar 41,7\% dan betina sebesar 48,3\% dari total sampel penelitian. Nisbah kelamin antara rajungan jantan dan betina adalah $0,8: 1$. Hal ini menunjukkan bahwa rajungan jantan dapat membuahi lebih dari satu rajungan betina.
\end{abstract}

Kata-Kata Kunci: Bio-ekologi, diskriptif, karakteristik habitat

\section{ABSTRACT}

This study aims to assess the size of the crabs are caught, analyzing the ratio of male and female, and analyze the habitat characteristics (salinity, temperature, $\mathrm{pH}$, and form of the substrate waters) in crab fishing area in the Ujung Vilage of East Lombok District.This research is a descriptive study using survey methods in data collection. The parameters studied are biological and ecological parameters. Biological parameters measured were sex and carapace width, while the ecological parameters are temperature, salinity, and $\mathrm{pH}$ of the water and the form of the substrate.The results showed that the water quality in the study area were very feasible for the life of crab, with a distribution of temperature between $29^{\circ} \mathrm{C}-30^{\circ} \mathrm{C}$. Salinity waters in the study area ranged from 31 to $32 \mathrm{ppt}$, and water $\mathrm{pH}$ value in the study site ranged from 7.2 to 7.5.Karaps wide distribution crab dominated by width exceeding $100 \mathrm{~mm}$ in both males and females. The proportion of carapace width of male crabs are caught with a width exceeding $100 \mathrm{~mm}$ is $41.7 \%$ and females at $48.3 \%$ of the total sample.Rajungan sex ratio between males and females was $0.8: 1$. This shows that the male crab can fertilize more than one female crabs.

Keywords: Bio-ekologi, descriptive, habitat characteristics 


\section{Pendahuluan}

Indonesia memiliki keanekaragaman hayati laut yang sangat tinggi dan dapat dimanfaatkan sebagai bahan pangan dan bahan industri. Salah satu sumberdaya tersebut adalah rajungan (Portunus pelagicus) yang merupakan salasatu komoditas perikanan yang bernilai ekonomis penting karena permintaannya tinggi dan merupakan komoditas ekspor dengan harga yang tinggi. Harga jual dagingrajungan (rajungan kupas) dari pengumpul untuk kategori jumbo (daging utuh dari bagian dalam pangkal kaki pendayung) mencapai Rp.200 000/kg (Komunikasi pribadi dengan pengumpul rajungan di Dusun Ujung, Desa Pemongkong, Kecamatan Jerowaru, Kabupaten Lombok Timur pada Oktober 2015).

Rajungan hasil tangkapan para nelayan dijual pada para pengumpul (bakul). Para pengumpul ini menjual rajungannya kepada para bandar besar yang merupakan agen pembelian dari perusahaan-perusahaan besar (eksportir) rajungan. Oleh karena itu produksi rajungan sering tidak tercatat oleh petugas dari Dinas Perikanan setempat. Tidak adanya data produksi ini mengakibatkan sulitnya mengetahui besar produksi yang dihasilkan. Di lain pihak, pasar yang luas dan harga yang tinggi ini menjadi pemicu berkembangnya perikanan rajungan.

Hingga saat ini besarnya tingkat pemanfaatan dan perdagangan rajungan tidak diimbangi dengan pengetahuan tentang cara melestarikan sumberdaya tersebut. Hal ini dapat berakibat pada terjadinya penurunan stok sumberdaya rajungan. Pengetahuan tentang cara melestarikan sumberdaya rajungan dapat meliputi pengetahuan tentang berapa besar tingkat rekruitmen, berapa besar tingkat mortalitas, kapan waktu yang tepat melakukan penangkapan, berapa ukuran yang layak tangkap, berapa ukuran pertama matang gonad, dan bagaimana karakteristik habitatnya. Melalui pengetahuan-pengetahuan tersebut dapat disusun suatu pengelolaan perikanan yang tidak hanya berorientasi pada produksi tapi juga pada ekosistem.

Di wilayah perairan Dusun Ujung, seperti halnya wilayah perairan lain di Provinsi Nusa Tenggara Barat (NTB), memiliki karakteristik permasalahan yang relatif sama yaitu sumberdaya perikanan terutama rajungan yang terbatas dan jumlah armada yang relatif banyak dibandingkan dengan wilayah pengelolaan perikanan yang lain. Kondisi demikian dapat mengakibatkan terjadinya tangkap lebih (over fishing) tehadap sumberdaya rajungan.

Salah satu penyebab terjadinya overfishing adalah dilakukannya penangkapan secara terus-menerus oleh nelayan. Penangkapan yang terus menerus karena ketidaktahuan mengenai fase-fase perkembangan biologis rajungan, mengakibatkan tingkat rekruitmen menjadi menurun. Menurut Widodo dan Suadi (2008) terdapat beberapa ciri yang dapat menjadi indikasi suatu perikanan sedang menuju kondisi overfishing yaitu waktu 
melaut menjadi lebih lama dari biasanya, lokasi penangkapan menjadi lebih jauh, ukuran mata jaring menjadi lebih kecil, produktivitas (hasil tangkapan per satuan upaya/CPUE) menurun, dan ukuran organisme target semakin kecil.

$$
\text { Pesatnya perkembangan }
$$

perusahaan eksportir rajungan dengan bahan baku bersumber dari hasil tangkapan nelayan setempat mengakibatkan sangat banyaknya nelayan yang melakukan penangkapan rajungan dengan frekuensi penangkapan yang terus-menerus, sehingga dapat mengurangi stok rajungan di perairan. Sebenarnya bahan baku untuk keperluan ekspor dapat dipasok dari kegiatan budidaya, namun hingga sekarang kegiatan budidaya belum berhasil dengan baik. Status perkembangan teknologi budidaya masih dalam tahap pembenihan dan usaha pembesaran skala kecil. Kondisi demikian mengakibatkan pasokan bahan baku hanya mengandalkan hasil tangkapan dari laut yang dapat berakibat penurunan stok. Berkurangnya stok rajungan selain diakibatkan oleh jumlah armada perikanan rajungan yang banyak, juga diduga sebagai akibat pola penangkapan yang tidak memperhatikan fase-fase biologis rajungan serta penggunaan alat tangkap yang tidak selektif. Penyebab hal tersebut di atas diantaranya adalah pengetahuan nelayan tentang cara menjaga kelestarian sumberdaya rajungan yang masih sangat minim, sehingga mereka tidak mengetahui waktu dan tempat yang tepat untuk melakukan penangkapan dan ukuran yang layak untuk ditangkap. Selain minimnya pengetahuan nelayan, tidak adanya regulasi dari pemerintah yang tegas dan mengikat juga mengakibatkan pola perikanan rajungan tidak mengindahkan kelestarian sumberdaya dan dapat menimbulkan berkurangnya stok rajungan akibat over fishing.

Habitat rajungan yang baik juga akan menentukan karakteristik daerah penangkapannya. Melalui pengetahuan tentang karakteristik daerah penangkapan dan daerah pemijahan, maka dapat dilakukan pengelolaan dengan membatasi atau membagi perairan menjadi beberapa kawasan seperti zona inti pada kawasan konservasi yang merupakan daerah pemijahan, zona pemanfaatan terbatas dan kawasan pemanfaatan atau penangkapan yang merupakan habitat rajungan dewasa. Dengan pembatasan wilayah dan ukuran ini maka diharapkan tingkat rekruitmen akan meningkat.

Dalam rangka menyelamatkan komoditi rajungan dari alam, maka aspek-aspek biologi yang menyangkut ukuran layak tangkap dan aspek ekologi yang meliputi karakteristik utama habitat perlu segera diketahui.

Tujuan penelitian ini adalah mengkaji ukuran rajungan dan menganalisis karakteristik habitat rajungan (salinitas, suhu, bentuk dasar perairan) di daerah penangkapan rajungan di perairan Dusun Ujung.

\section{Bahan dan Metode}

Penelitian dilakukan selama 8 bulan dimulai pada bulan Mei sampai Desember 2016. Lokasi penelitian 




Gambar 1. Peta lokasi penelitian

Data dikumpulkan dengan menggunakan metode survei dan dokumentasi. Sampel rajungan diambil sebesar $10 \%$ dari hasil tangkapan nelayan, hal ini dilakukan untuk memenuhi standard minimal pengambilan sampel secara statistik.

Pengambilan sampel substrat dan air dilakukan sebelum setting jaring atau setelah hauling. Sebelum dilakukan penangkapan rajungan terlebih dahulu dilakukan pengukuran kedalaman dan pengambilan sampel substrat atau sedimen dasar perairan serta pengambilan sampel air untuk mengamati kualitas air yang meliputi salinitas, suhu, dan $\mathrm{pH}$. Pengukuran salinitas, $\mathrm{pH}$ dan suhu dilakukan secara in situ. Setelah melakukan penangkapan rajungan, maka dilakukan pengukuran bobot total, jumlah dan jenis rajungan hasil tangkapan, pemisahan dan penghitungan rasio jenis kelamin. Selanjutnya rajungan yang telah diketahui jenis, bobot, dan jenis kelaminnya diukur panjang dan lebar karapasnya.

Parameter yang diamati meliputi panjang dan lebar karapas, serta jenis kelamin. Panjang karapas diukur dengan menggunakan jangka sorong atau kaliper (dengan ketelitian 0,05 $\mathrm{mm})$. Panjang rajungan diukur dari anterior (tempat mata berada) ke arah posterior (tempat abdomen berada) sedangkan lebarnya diukur dari duri lateral terpanjang yang berada di sisisisi tubuhnya (Gambar 2). 


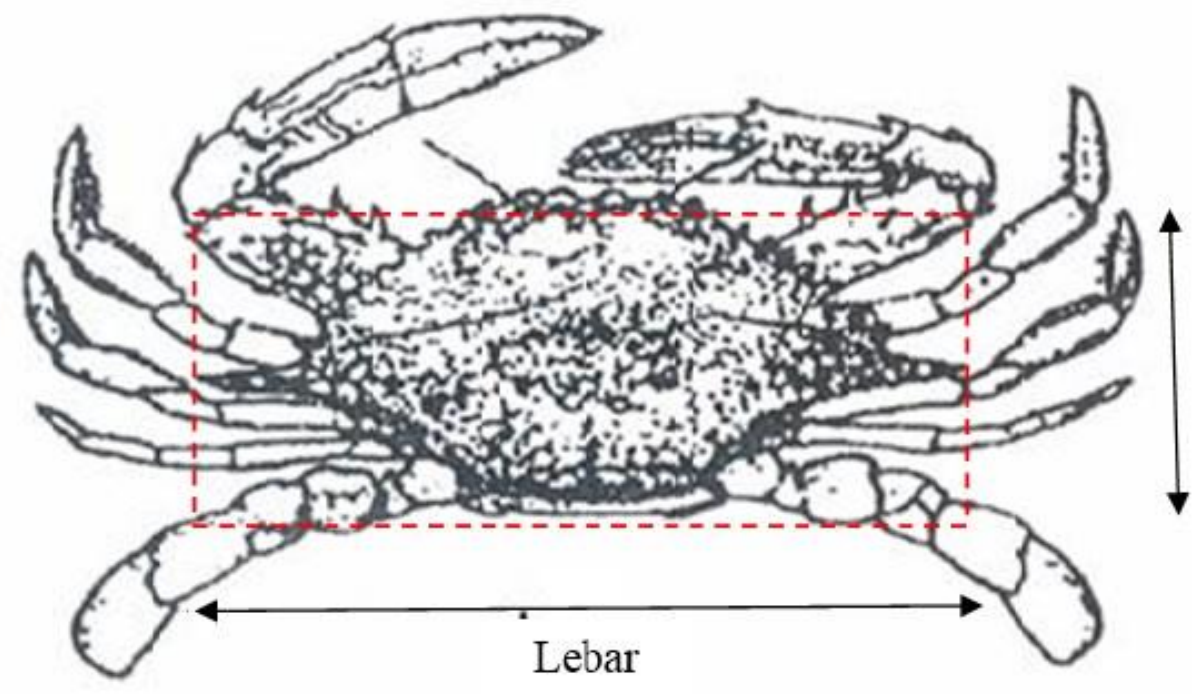

Gambar 2. Sistem pengukuran panjang dan lebar karapas rajungan.

Penentuan jenis kelamin dibutuhkan untuk melakukan analisis seks rasio dan pola reproduksi rajungan serta distribusi temporal maupun spasial jenis kelamin.

Analisis data meliputi karakteristik habitat dapat diketahui melaluianalisis deskriptif dengan menyajikan data-data ekologis. Analisis ini akan dilakukan terhadap data tentang kondisi fisika-kimia perairan yang meliputi variable kedalaman, suhu, salinitas, dan $\mathrm{pH}$. Determinasi jenis rajungan dapat dilakukan dengan analisis morfologi dan anatomis rajungan dengan melihat organ-organ eksternal dan internal. Hasil analisis di sajikan secara deskriptif.

\section{Hasil dan Pembahasan}

\subsection{Hasil}

Karakteristik Habitat Rajungan

Sampel substrat yang diambil dari kedalaman 3-12 m, menunjukkan kondisi substrat didominasi oleh fraksi pasir diikuti oleh fraksi lumpur dan fraksi liat. Hasil analisis secara deskriptif menunjukkan bahwa kelas tekstur substrat setiap stasiun sampling hampir sama yaitu didominasi lempung (loam) baik lempung berpasir (sandy loam) maupun lempung berliat (clay loam). Kondisi substrat seperti ini merupakan karakteristik umum perairan pesisir di wilayah Dusun Ujung Lombok Timur.

Kualitas air yang diamati meliputi suhu, salinitas, $\mathrm{pH}$ dan kedalaman perairan. Hasil penelitian menunjukkan bahwa suhu perairan bervariasi antara $29^{\circ} \mathrm{C}-30^{\circ} \mathrm{C}$. Kisaran suhu antara $29^{\circ} \mathrm{C}-30^{\circ} \mathrm{C}$ masih sangat layak bagi kehidupan rajungan. Variasi harian suhu di permukaan laut jarang melebihi $2^{0} \mathrm{C}$ atau $3^{0} \mathrm{C}$, meskipun dapat mencapai $2^{0} \mathrm{C}$ atau $3^{0} \mathrm{C}$ di perairan pantai yang dangkal (Millero dan Sohn, 1992).

Rajungan memiliki toleransi yang tinggi terhadap perubahan salinitas. Sebarannya yang sangat luas 
Jurnal Biologi Tropis, Juli 2016: Volume 16 (2):94-105

membuktikan toleransinya terhadap

perubahan salinitas. Salinitas perairan di

daerah penelitian berkisar dari 31

sampai 32 ppt. Rentang salinitas

tersebut masih sangat baik bagi

kelangsungan hidup dan pertumbuhan rajungan.

Nilai pH perairan di lokasi penelitian berkisar antara 7.2 sampai 7.5. Hal ini menunjukkan bahwa perairan lebih netral. Nilai $\mathrm{pH}$ yang berbeda didapatkan pada substrat dasar perairan yaitu sebesar 6.5 sampai 7.8. Kandungan bahan organik menjadikan dasar perairan lebih bersifat asam sampai netral.

ISSN: 1411-9587

Distribusi Lebar Karapas Rajungan

Hasil penelitian menunjukkan bahwa interval kelas yang tertangkap dan menjadi sampel penelitian ini adalah berkisar antara 95,01 - 145,05 mm untuk jantan dan 101,06 - 155.02 mm untuk betina. Proporsi jumlah rajungan jantan yang tertangkap dengan lebar karapas $\geq 100 \mathrm{~mm}$ sebesar $41,7 \%$ dari total jumlah rajungan yang menjadi sampel penelitian ini yaitu sebanyak 120 ekor . Dilain pihak, proporsi jumlah rajungan betina yang tertangkap dengan lebar karapas $\geq 100 \mathrm{~mm}$ sebesar $48.3 \%$ (Gambar 3).

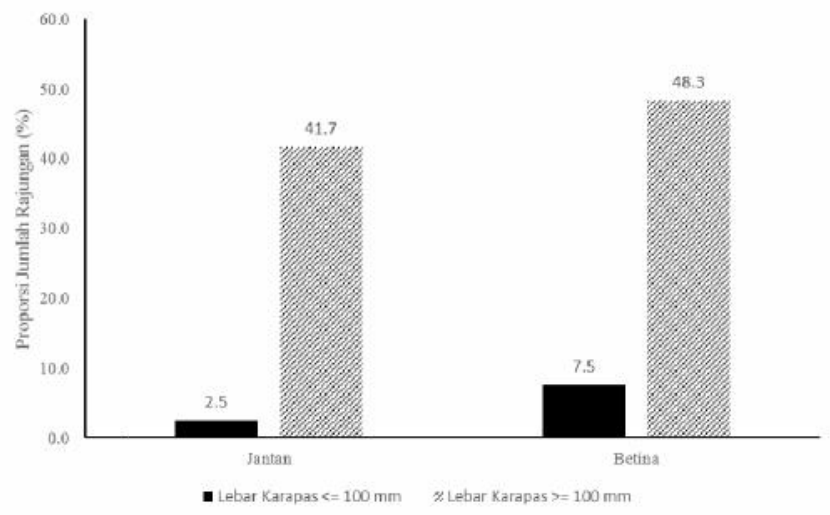

Gambar 3. Proporsi jumlah rajungan jantan dan betina yang tertangkap

Rata-rata lebar karapas rajungan

jantan yang tertangkap sebesar 118,2 mm dengan standar deviasi sebesar 9,7, sedangkan untuk rajungan betina sebesar 124,1 $\mathrm{mm}$ dengan standar deviasi sebesar 12,4 (Gambar 4). 


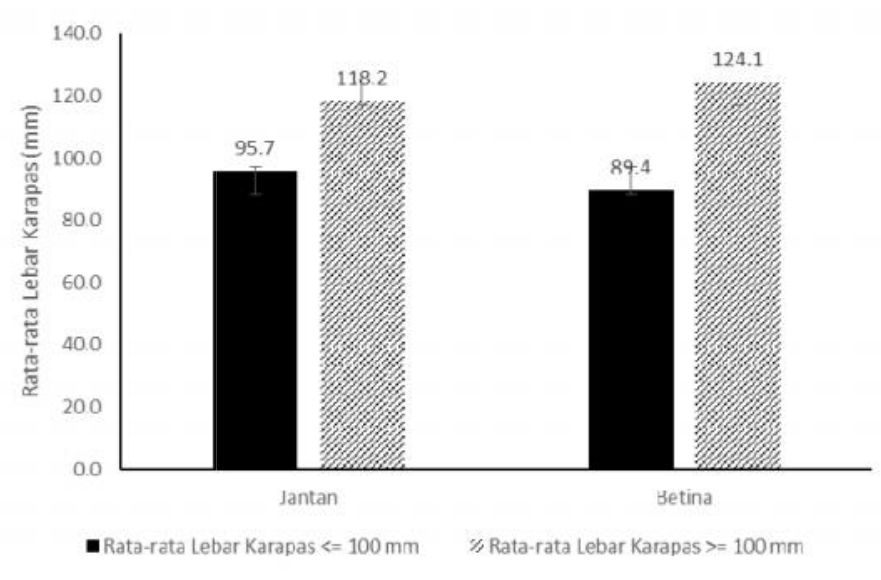

\subsection{Pembahasan}

Kondisi substrat yang ditemukan di daerah penelitian tersebut hampir sama dengan penelitian yang dilakukan oleh Djunaedi (2009) melaporkan bahwa substrat pasir, lumpur dan liat tidak berbeda nyata dalam mempengaruhi kelulushidupan crablet rajungan. Djunaidah (2004) melaporkan juga bahwa pengaruh tiga jenis substrat lumpur, pasir dan campuran keduanya terhadap parameter reproduksi kepiting. Hasil penelitian menunjukkan bahwa tidak ada pengaruh nyata antara jenis substrat dan karakteristik reproduksi.

Rajungan tersebar luas pada perbedaan substrat dasar perairan.Yokes et al. (2007) menemukan rajungan pada perairan dengan substrat pasir halus (fine sand) pada kedalaman $0.5 \mathrm{~m}$. Foka et al. (2004) menemukan rajungan pada perairan dengan dasar lumpur berpasir. Di pantai Palamut Buku Datca Peninsula Turki, rajungan ditemukan pada pantai berbatu kerikil (gravel beach). Rajungan betina membutuhkan substrat berpasir untuk kesuksesan pengeluaran telurnya dan menempelkannya pada pleopod
(Champbell, 1984). Hal yang sama dinyatakan oleh Sumpton et al. (1994) bahwa persentase rendah dari rajungan betina dalam perikanan komersial di Teluk Moreton Australia selama periode pemijahan telah memperlihatkan adanya migrasi betina dewasa menuju bagian yang berpasir untuk mengeluarkan telurnya.

Beberapa literatur menunjukkan bahwa rajungan merupakan organisme yang mampu mentolerir kisaran suhu yang luas. Rajungan terdistribusi pada daerah yang sangat luas dari perairan tropis hingga subtropis yang memiliki perbedaan suhu relatif besar. Beberapa penelitian di daerah tropis telah dilakukan antara lain oleh Sukumaran dan Neelakantan (1996) yang mengambil sampel di barat daya pantai India, Chande dan Mgaya (2004) dengan mengambil sampel di perairan Pantai Dareel Salam Tanzania; Batoy, et al. (1980) yang mengambil sampel di perairan Philipina. Sementara itu sebaran rajungan pada daerah subtropis telah ditemukan melalui beberapa penelitian, seperti yang dilakukan antara lain oleh Smith (1982) di Australia Selatan, Sumpton et al. (1994) di Teluk 
Moreton Queensland Australia dan de Lestang et al. (2000) yang mengambil sampel rajungan diTeluk Antalya Turki.

Suhu dan salinitas merupakan faktor penting yang mempengaruhi distribusi, aktivitas dan pergerakan rajungan. Menurut Levinton (1982) faktor suhu menentukan siklus musiman gametogenesis dan pemijahan. Peranan suhu dan musim telah nyata dalam siklus reproduksi. Gametogenesis dan pemijahan biasanya berhubungan dengan perubahan musim dan suhu kritis yang berkontribusi bagi permulaan pemijahan. Fakta-fakta tentang luasnya sebaran rajungan baik di daerah tropis maupun sub tropis telah membuktikan bahwa rajungan termasuk organisme eurytermal yang dapat beradaptasi pada rentang suhu yang sangat besar.

Rajungan memiliki toleransi

yang tinggi terhadap perubahan salinitas. Sebarannya yang sangat luas membuktikan toleransinya terhadap perubahan salinitas. Rajungan merupakan organisme yang memiliki pergerakan yang relatif jauh. Keberadaannya ditemukan dari kedalaman kurang dari $1 \mathrm{~m}$ di daerah intertidal dan muara sungai sampai kedalaman 60 m (Razek,1988). Muara sungai atau estuari merupakan perairan dengan salinitas campuran antara air laut dan air tawar. Salinitas pada daerah ini jauh lebih kecil dari daerah lepas pantai. Berdasarkan fakta tersebut rajungan mampu mentolerir salinitas pada rentang cukup tinggi. Menurut Chande dan Mgaya (2003) rajungan mampu mentolerir kisaran salinitas yang luas antara 9 ppt -39 ppt.
Hasil penelitian terhadap lebar karapas menunjukkan bahwa rajungan yang tertangkap di lokasi penelitian mayoritas dengan lebar karapas $\geq 100$ mm baik jantan maupun betina. Hal ini sangat sesuai dengan Peraturan Menteri Kelautan dan Perikanan nomor 1 tahun 2015 yang melarang penangkapan kepiting dengan lebar karapas $<100$ mm. Indikator keberlanjutan penangkapan rajungan dapat dilihat dari distribusi ukurannya. Jika ditetapkan ukuran layak tangkap sebesar $100 \mathrm{~mm}$ maka sebagian besar ukuran tangkapan berada antara ukuran pertama kali matang gonad dan panjang maksimum tiap upaya. Menurut Froese dan Binohlan (2000), apabila sebagian besar hasil tangkapan berada dalam kisaran antara panjang pada pertama kali matang gonad dan panjang maksimum tiap upaya mengindikasikan laju eksploitasi berkelanjutan.

Alat tangkap jaring tasik yang digunakan oleh nelayan Dusun Ujung ini relatif lebih selektif juka dibandingkan dengan alat tangkap bubu. Hal ini sesuai dengan hasil yang dilaporkan oleh Susanto dan Irnawati (2012), dimana alat tangkap bubu yang digunakan pada skala laboratorium hanya dapat meloloskan rajungan dengan ukuran $70 \mathrm{~mm}$.

Hasil ini menunjukkan bahwa tingkat selektifitas alat yang digunakan oleh nelayan Dusun Ujung sudah sangat baik. Alat yang digunakan untuk menangkap rajungan di perairan wilayah ini adalah jaring tasik, dengan ukuran mata jaring sebesar 3,5 inch atau $8,9 \mathrm{~cm}$. Hal ini menyebabkan rajungan dengan ukuran lebih kecil dari mata 
jaring tersebut dapat lolos. Selain itu hasil tangkapan ini menunjukkan keberlanjutan penangkapan rajungan di wilayah perairan tersebut sangat baik. Hal ini disebabkan karena mayoritas rajungan yang tertangkap dalam kondisi telah matang gonad atau dengan kata lain sudah pernah melakukan pemijahan.

Hasil penelitian ini sesuai
dengan perhitungan
menggunakan rumus Spearman-Karber
(Udupa,1986 dalam Fischer dan Wolff, 2006) didapatkan ukuran panjang pertama kali matang gonad untuk rajungan jantan sebesar $63 \mathrm{~mm}$ atau $128 \mathrm{~mm}$ ukuran lebarnya, sedangkan rajungan betina sebesar 48 $\mathrm{mm}$ atau $101 \mathrm{~mm}$ ukuran lebarnya. Hasil penelitian ini hampir sama dengan penelitian yang dilakukan oleh Ningrum et al (2015) di Perairan Betahwalang, dimana rata-rata lebar karapas rajungan jantan yang tertangkap berkisar antara 121 - $130 \mathrm{~mm}$ baik pada rajungan jantan dan betina.

Pemberlakuan regulasi ukuran minimum yang legal akan menjaga kelestarian sumberdaya rajungan dan pasokan bahan baku industri pengalengan rajungan yang masih mengandalkan hasil tangkapan dari laut.

\section{Kesimpulan}

Dari hasil penelitian dapat ditarik kesimpulan :

1. Kondisi substrat didominasi oleh fraksi pasir diikuti oleh fraksi lumpur dan fraksi liat.
2. Kualitas air di daerah penelitian sangat sangat layak bagi kehidupan rajungan, dengan sebaran suhu antara $29^{\circ} \mathrm{C}-30^{\circ} \mathrm{C}$, salinitas perairan di daerah penelitian berkisar dari 31 sampai 32 ppt, dan Nilai $\mathrm{pH}$ perairan di lokasi penelitian berkisar antara 7.2 sampai 7.5.

3. Distribusi lebar karaps rajungan di dominasi oleh lebar diatas $100 \mathrm{~mm}$ baik jantan maupun betina. Proporsi lebar karapas rajungan jantan yang tertangkap dengan lebar diatas 100 $\mathrm{mm}$ adalah sebesar $41,7 \%$ dan betina sebesar $48,3 \%$ dari total sampel penelitian.

\section{Daftar Pustaka}

Barnes RD. 1987. Invertebrate Zoology. 5th.Edition. Saunders. College Publishing. Philadelpia. 893 p.

Barnes RSK, RN Hughes. 1992. An Introduction to Marine Ecology. Second Edition. Blackwell Scientific Publications. London. 351 hal.

Bryars SR, JN Havenhand. 2004. Temporal and spatial distribution and abundance of blue swimmer crab (Portunuspelagicus) larvae in a temperate gulf. Marine and Freshwater Research 55(8):809818.

ChampbellGR. 1984. A comparative study of adult sexxal behavior and larval ecology of three commercial important portunid crab from the Moreton Bay region of Queensland Australia. 
University of

Queensland.Australia.

Chande AI, YD Mgaya. 2004. The Fishery ofPortunuspelagicus and Species Diversity of portunid crab along the Coast of Dar es Salaam, Tanzania. Western Indian Ocean. J. Mar. Sci. 2 (1): 75-84.

Chande AI, YD Mgaya. 2004. Food habits of the blue swimming crab Portunuspelagicus along the coast of Dar es Salaam, Tanzania. Western Indian Ocean. J. Mar. Sci. 3 (1): 37-42.

Chande AI, Y.D. Mgaya. 2004. Food habits of the blue swimming crab Portunuspelagicus along the coast of Dar es Salaam, Tanzania. Western Indian Ocean J. Mar. Sci. 3 (1): 37-42.

DahuriR. 2003

KeanekaragamanHayatiLaut. Aset Pembangunan Berkelanjutan Indonesia. PT GramediaPustakaUtama.

Jakarta. 412 hal.

DjunaidahIS. 2004.

KajianPolaPemijahanKepitingBa kau (Scylla paramamosainEstampador) Dan PeningkatanPenampilanReprodu ksinyaMelaluiPerbaikanKualitas PakanDalamSubstratPemelihara anTeruji. Disertasi. SekolahPascasarjana.

InstitutPertanian Bogor. 171 hal. DjunaediA. 2009.

KelulushidupandanPertumbuhan CrabletRajungan (Portunuspelagicus Linn.) padaBudidayadenganSubstratDa sar yang Berbeda. JurnalIlmuKelautan.14 (I): 2326.

HartutiR. 1996.

Studipendahuluantentangtoleran sirajungan (Portunuspelagicus) padasalinitas medium yang berbeda. JurnalIlmuKelautan. 1(2):1-3.

Fischer S“onke, MWolff . 2006. Fisheries assessment of Callinectesarcuatus(Brachyura, Portunidae) in the Gulf of Nicoya, Costa Rica. Fisheries Research 77: 301-311.

Foka MC, G Kondylatos, P.S. Economidis.2004.Occurrence of the lessepsian species Portunuspelagicus (Crustacea) and Apogonpharaonis (Pisces) in the marine area of Rhodes Island. Medit. Mar. Sci. 5(1): 8389.

Froose R, C. Binohlan 2000. Empirical relationships to estimate asymptotic length, length at first maturity and length at maximum yield per recruit in fishes, with a simple method to evaluate length frequency data. J. Fish Biol. 56:758-773.

Hegner RW,JG Engemann. 1970. Invertebrate Zoology. Second Edition. The Macmillan Company. Collier-Macmillan Limited. London.

Josileen J, NG Menon. 2004. Larval Stage of the Blue Swimmer CrabPortunuspelagicus (Linnaeus, 1758)(Decapoda, Brachyura). Crustaceana77(7): 785-803. 
Kembaren D, Ernawati T, Suprapto. 2012. Biologidan parameter populasirajungan

(Portunuspelagicus) di perairan Bone dansekitarnya. PerikananLaut 7 (2) : 273-281.

McPherson R, K Brown. 2001. The Bioaccumulation of cadmium by the blue swimmer crab Portunuspelagicus L. The Science of the Total Environment 279:223-230.

Millero FJ, M Sohn. 1992. Chemical Oceanography.CRC Press. London.531 hal.

MoosaMK. 1980.

BeberapacatatanmengenaiRajung andariTeluk Jakarta danPulaupulauSeribu.

RangkumanHasilPenenlitianPelita II LON. Jakarta.

Nalan Go“' koDlu, Py' narYerlikayaa. 2003. Determinaton of proximate composition and mineral contents of blue crab (Callinectessapidus) and swim crab (Portunuspelagicus) caught off the Gulf of Antalya. Food Chemistry 80: 495-498

Nontji, A.1987. Laut Nusantara. PenerbitDjambatan .Jakarta.

Ningrum VP, A Ghofar, Ch Ain. 2015. BeberapaAspekBiologiPerikanan Rajungan (Portunuspelagicus) Di PerairanBetahwalang Dan Sekitarnya.

JurnalSaintekPerikanan 11(1): 62-71.

Nugraheni DI. 2016. PengelolaanPerikananRajungan (PortunusPelagicus Linnaeus, 1758)
DenganPendekatanEkosistem

(StudiKasus

:PerairanKabupatenPati,

ProvinsiJawa Tengah)[Thesis].

Bogor (ID): InstitutPertanian

Bogor.

Oemarjati BS, W Wardhana., 1990.

TaksonomiAvertebrata:

PengantarPraktikumLaboratoriu

$m$.

PenerbitUniversitasIndonesia.UI-

Press. Jakarta. 177 hal.

Oniam V,UBuathee, L Chuchit, T Wechakama. 2010. Growth and sexual maturity of blue swimming crab (Portunuspelagicus, Lineaus, 1758) reared earthen pond. Kasetsart University.Fisheries Research Bulletin. 34(1):20-27.

Razek FAA, SM Taha, AAAmeran. 2006. Population biology of the edible crab Portunuspelagicus (linnaeus) from Bardawil lagoon, northern Sinai, Egypt. Egyptian Journal of Aquatic Research. 32 (1): 401-418.

Secor DH,AHHines and AR Place. 2010. Japanese Hatchery-Based Stock Enhancment: Lesson for the Cheaspeak Bay Blue Crab. Maryland Sea Grand. College Park Maryland.

Setyadi I, ZI Azwar, Yunus, Kasprijo. 1997. Penggunaan Jenis Pakan Alami dan Buatan dalam Pemeliharaan Larva Kepiting Bakau Scylla Serrata. Jurnal Penelitian Perikanan Indonesia: $73-77$.

Smith H. 1982. Blue Crab in South Australia-their status, potensial and biology. SAFIC 6:6-9. 
Stephenson W, B. Chambell. 1959. The

Australians Portunids (Crustacea :Portunidae).IV. Remaining Genera.

SumptonWD, MA Potter and GS Smith.1994. Reproductions and Growth of the Commercial Sand Crab (Portunuspelagicus) in Moreton Bay Queensland. Asian Fisheries Science 7:103-133.

Sukumaran KK, Neelakantan B. 1996.

Relative growth and sexual maturity in the marine crabs, Portunus (Portunus) sanguinolentus (Herbst) and Portunus (Portunus) pelagicus (Linnaeus) along the south-west coast of India. Indian J. Fish. 43: 215-223.

Susanto A, R Irnawati. 2012. PenggunaanCelahPelolosanPadaB ubuLipatKepitingBakau (SkalaLaboratorium).

JurnalPerikanandanKelautan II (2): 71-78.

Svane I, GE Hooper. 2004. Blue Swimmer Crab (Portunuspelagicus) Fishery. Fishery Assessment Report to PIRSA for Blue Crab Fishery Management. Committee South Australian Research and
Development

Institute.AquaticSciences

Publication. No.RD03/0274.

Webber HH, HV Thurman.1991. Marine Biology. Second Edition. Harper Collins Publishers. Inc. New York. 424 p.

Williams MJ. 1982. Natural food and feeding in the commercial sand crab Portunuspelagicus Linnaeus, 1766 (Crustacea: Decapoda: Portunidae) in Moreton Bay Queensland. Journal of Experimental Marine Biology and Ecology59(2): 165-176.

Xiao Y, M Kumar. 2004. Sex ratio, and probability of sexual maturity of female at size, of the blue swimmer crabs, PortunuspelagicusLinneaus, off southern Australia. Jour.Fisheries Research 68:271-282.

Zairion, WardiatnoY, danFahrudin A. 2015. Sexual maturity, reproductive pattern and spawning female population of the blue swimming crab, Portunuspelagicus (Brachyura: Portunidae) in East Lampung coasts water, Indonesia. Science and Technology 8 (7): 596-607. 